ERRATUM

Davide Csermely • Luca Bagni

\title{
The predatory behaviour of common kestrels facing various types of prey
}

\section{J Ethol (2003) 21:107-110}

There were errors in the printed version of this article.

In the Results section, the first sentence of the fifth paragraph and the second sentence of the sixth paragraph should read as follows, respectively:
After grasping, the kestrels struck prey with their beak at variable frequencies $\left(\chi_{r}^{2}=24.36, d f=3, P<0.001\right)$.

Such a latency differed greatly between prey $\left(\chi_{r}^{2}=23.80\right.$, $d f=3, P<0.001)$ ranging from $2.78 \pm 0.7 \mathrm{~s}$ in tests with the earthworm as prey to $230.0 \pm 60.1 \mathrm{~s}$ in tests with the mouse.

The publisher sincerely apologizes for any inconvenience these errors may have caused.

D. Csermely $(\varangle) \cdot$ L. Bagni $^{1}$

Dipartimento di Biologia Evolutiva e Funzionale, Università di Parma,

Parco Area delle Scienze 11A, 43100 Parma, Italy

Tel. +39-0521-905632; Fax +39-0521-905657

e-mail: csermely@biol.unipr.it

Present address:

${ }^{1}$ Via Gambuzzi 115, 42020 Rivalta di Reggio Emilia, Italy

The online version of the original article can be found at http://dx.doi.org/10.1007/s10164-002-0083-6 